\title{
Evaluation of Fatigue Life Reliability of Steering Knuckle Using Pearson Parametric Distribution Model
}

\author{
E. A. Azrulhisham, ${ }^{1}$ Y. M. Asri, ${ }^{2}$ A. W. Dzuraidah, ${ }^{3}$ N. M. Nik Abdullah, ${ }^{3}$ \\ A. Shahrum, ${ }^{3}$ and C. H. Che Hassan ${ }^{3}$ \\ ${ }^{1}$ Malaysia France Institute, Universiti Kuala Lumpur, Bandar Baru Bangi, 43650 Selangor, Malaysia \\ ${ }^{2}$ Faculty of Mechanical Engineering, Universiti Teknikal Malaysia Melaka, 76100 Melaka, Malaysia \\ ${ }^{3}$ Faculty of Engineering and Built Environment, Universiti Kebangsaan Malaysia, 43600 Bangi Selangor, Malaysia
}

Correspondence should be addressed to E. A. Azrulhisham, engku@mfi.unikl.edu.my

Received 8 May 2010; Revised 17 October 2010; Accepted 10 December 2010

Academic Editor: Ratna Babu Chinnam

Copyright (C) 2010 E. A. Azrulhisham et al. This is an open access article distributed under the Creative Commons Attribution License, which permits unrestricted use, distribution, and reproduction in any medium, provided the original work is properly cited.

\begin{abstract}
Steering module is a part of automotive suspension system which provides a means for an accurate vehicle placement and stability control. Components such as steering knuckle are subjected to fatigue failures due to cyclic loads arising from various driving conditions. This paper intends to give a description of a method used in the fatigue life reliability evaluation of the knuckle used in a passenger car steering system. An accurate representation of Belgian pave service loads in terms of response-time history signal was obtained from accredited test track using road load data acquisition. The acquired service load data was replicated on durability test rig and the SN method was used to estimate the fatigue life. A Pearson system was developed to evaluate the predicted fatigue life reliability by considering the variations in material properties. Considering random loads experiences by the steering knuckle, it is found that shortest life appears to be in the vertical load direction with the lowest fatigue life reliability between 14000-16000 cycles. Taking into account the inconsistency of the material properties, the proposed method is capable of providing the probability of failure of mass-produced parts.
\end{abstract}

\section{Introduction}

The steering knuckle is a part of the vehicle's steering and suspension system which undergoes time-varying loading during its service life. This system provides a means whereby driver can place his vehicle accurately where he wants it to be on the road. This system also means in keeping the vehicle stable on course regardless of irregularities in the surface over which the vehicle is travelling. Any failure in these components results immediately in loss of the orientation of the vehicle [1]. This paper will focus on McPherson strut steering knuckle which is mainly used in the steering system of the front-wheel drive vehicles. This McPherson strut steering knuckle system consist of a strut mount at the top, ball joint at the bottom, and a steering arm on the side as illustrated in Figure 1. The wheel spindle fits through a hole in the centre. Since it is connected to the steering parts and strut assembly from one side and the wheel hub assembly from the other, the component has complex restraint and constraint conditions and tolerates a combination of loads [2]. In this study, driving a vehicle over Belgian pave applies cyclic loads to the steering knuckle through the strut mount, ball joint and steering tie rod.

In general, fatigue life assessment of the component could be obtained using four different methodologies: the nominal stress-life $(\mathrm{SN})$ approach, the local strain-life $(\varepsilon \mathrm{N})$ approach, the fatigue crack growth approach or the twostage approach which consist of a combination of the third approach with either the first or the second approach. The nominal stress-life approach mainly deals with linear elastic stresses and strains, and hence it is applicable to components experiencing high cycle fatigue such as suspension systems and crankshaft where loading cycles to failure exceeds $10^{5}$. The local strain-life approach instead has been developed to model the elastic-plastic deformation of material. This approach is typically valid for low cycle fatigue with loading 


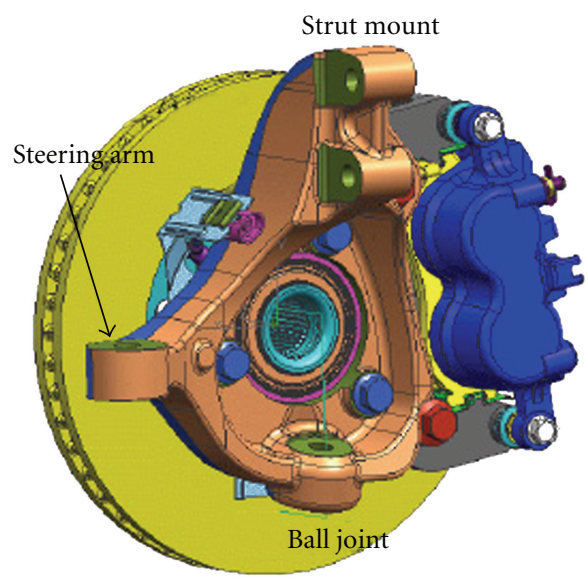

FIGURE 1: Steering knuckle system.

cycle ranges from $10^{3}$ to $10^{5}$ [3]. The crack growth approach is based on fracture mechanics and damage tolerance design.

In terms of automotive component, the strain-life approach is a more generally applicable method than stresslife and is used widely where engineers are trying to design components to a finite life [4]. However, this approach suffers from serious limitation when applied to practical production components due to an inadequate algorithm when dealing with real surface conditions and multiaxial stress states [3]. The crack growth approach in other hand requires knowledge of defects and cracks, and thus necessitates nondestructive inspection, making this approach cost prohibitive for the ground vehicle industry at present [5].

For the case of stress-life and strain-life where the scatter in fatigue life was neglected, it is sufficient to know the relationship between load and life using typical $\mathrm{SN}$ or $\varepsilon \mathrm{N}$ relationship. In this approach, fatigue life is predicted by associating the information from the cycle counting (typically represented by the rainflow matrices) of the variable amplitude service loads and the material properties of the component represented by the $\mathrm{SN}$ or $\varepsilon \mathrm{N}$ curve [6]. However, in terms of mass production, fatigue properties of material used in the fabrication of components cannot be exactly consistent in quality even if ordering of the material is made with the same material specification. Material properties of components used in the fabrication cannot be exactly consistent due to uncertainties associated with the size effect, machining and manufacturing conditions. These uncertainties factors should be considered as random variables that results in variation of the fatigue life curves.

Statistical trends about the fatigue life can be acquired from fatigue experiment. The stair-case method is the most well-known procedure to obtain an estimate of the mean value and the standard deviation [7]. This approach is inappropriate due to the increasing pressures of shortened development cycles and the desire to save costs since it requires long lasting test in order to obtain a reasonable confidence level. In dealing with variation of the fatigue life due to uncertainties in mechanical properties, several researchers and organizations over the last 50 years have accumulated statistical distribution of material property data. However, property data is still not available for many materials or is not made generally available by the manufacturer of the product [8]. In general, the variation in material properties which characterized the fatigue life curve of the material is assumed to be normally distributed for it is a reasonable model for many processes or physical properties $[9,10]$. Although this may be considered to be reasonable, it should be recognized that the actual distribution function is not really known [11].

In this study, variation in the slope and intercept of the fatigue life curve of a steering knuckle which characterized the deviation in fatigue life is selected as random variables. Pearson parametric statistical model is used to provide approximate of random variables based on the distribution properties of the fatigue life. Fatigue life of the component under random loading conditions is estimated using rainflow cycle counting, PSN curve, and cumulative damage accumulation method. Distribution family of fatigue life estimates by variation in fatigue life curves can be identified using Pearson's criterion. Probability density function of the fatigue life estimates is calculated using statistical moment of the identified distribution and the fatigue life reliability is then calculated from the obtained probability density function.

\section{Methodology}

2.1. Finite Element Analysis and Materials. In the case of steering knuckle, loads are simultaneously applied in several directions, producing stresses with no bias to a particular direction. In this study, critical stress location of the steering knuckle was identified by developing Finite Element (FE) model based on MSC/Fatigue and absolute maximum principal stress procedures was adopted to relate multiaxial to uniaxial load cases. The inputs to the process are an FE model of the component, a set of cyclic material properties and a set of representative loads in multiaxial direction. The FE model consists of 8-noded HEX elements as illustrated in Figure 2. In order to transfer loads to components as realistically as possible, they are applied using rigid elements at defined locations.

In this case, the steering knuckle model was constrained at the wheel centre and 12 load cases were applied, including three forces $(1,000 \mathrm{~N}$ in $X, Y$, and $Z)$ at the lower ball joint, steering arm and strut mount, and three moments $(1,000 \mathrm{~N}$ $\mathrm{mm})$ at the strut mount. These loading condition were then reduced using a peak-valley slicing technique, which extracts the maxima and minima from multiple channels while retaining the cycle sequence and phase information. An initial fatigue life assessment was carried out to compute elastic strain histories for each surface node. In the analysis, the stress and strain results were presented in local coordinate systems whose $z$-axes are outward surface normals. Results from the fatigue analysis show that the critical stress location of the steering knuckle was to be near the loading devices at the strut mount as shown in Figure 3. 


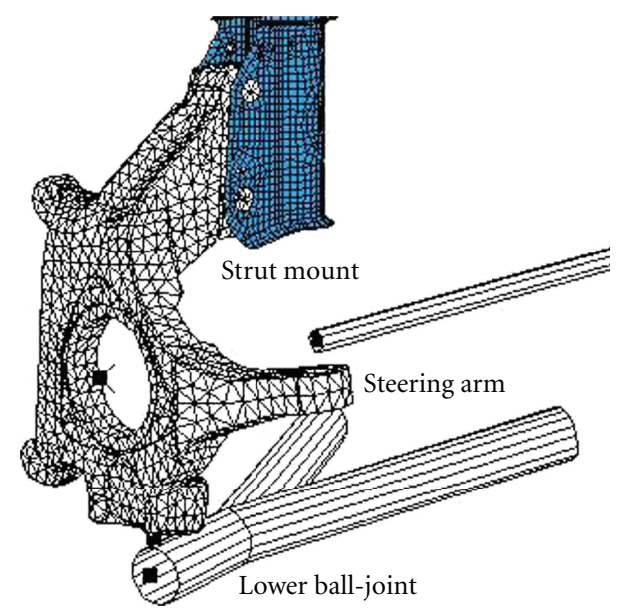

FIGURE 2: Finite element model for the steering knuckle.

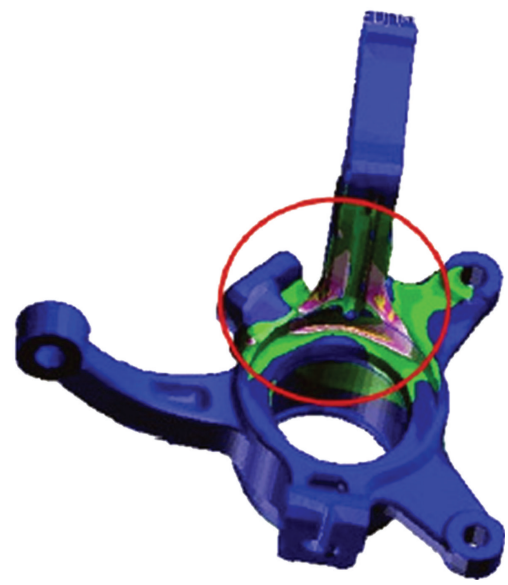

FIGURE 3: Critical stress location obtained by FEA.

TABLE 1: Chemical properties of FCD500-7.

\begin{tabular}{lcccccc}
\hline Element & $\mathrm{C}$ & $\mathrm{Cr}$ & $\mathrm{Si}$ & $\mathrm{Mn}$ & $\mathrm{Fe}$ & $\mathrm{Cu}$ \\
\hline Max $\%$ & 3.8 & 0.07 & 2.8 & 1.00 & 94.16 & 1.00 \\
\hline
\end{tabular}

TABLE 2: Material properties of FCD500-7.

\begin{tabular}{lc}
\hline Material name & FCD500 \\
\hline Yield strength & $360 \mathrm{MPa}$ \\
Ultimate tensile strength & $520 \mathrm{MPa}$ \\
Elastic modulus & $170 \mathrm{GPa}$ \\
Density & $7.14 E-06 \mathrm{~kg} / \mathrm{mm}^{3}$ \\
\hline
\end{tabular}

The steering knuckle material is spherical graphite cast iron FCD500-7, a high abrasion resistance material with low temperature shock property [12]. The chemical composition and mechanical properties for the FCD500-7 spherical graphite cast iron are shown in Tables 1 and 2, respectively.

2.2. Cyclic Tension Test. A sample of ten units of steering knuckle was subjected to a set of three different levels of cyclic bending fatigue load. This is achieved by clamping the six mounting points of the knuckle with a 2-ton clamping mechanism. The strut mount end of the knuckle was attached to a load arm, which will be connected to a motor with an eccentric mass to induce a moment. The process is illustrated in Figure 4. A mixture of zinc oxide powder with glycerine was painted on the critical stress location in order to ease the detection of crack initiation.

2.3. Vehicle Instrumentation. Mechanical and structural behaviors of components subjected to the desired load patterns were observed using micro measurement strain gauges. Strain gauges were strategically positioned at critical stress location of the steering knuckle to directly reflect the input loads experienced by the component. Quarter bridge circuits as well as shunt calibration were applied in order to convert electrical units measured by the strain gauge into the stress-time data.

2.4. Road Load Data Acquisition (RLDA). Loading sequences in terms of load-time histories of proving ground are acquired using the Road Load Data Acquisition (RLDA). The RLDA activity is established using a vehicle equipped with electronic data acquisition system (EDAQ) which consists of accelerometers and force transducers which are capable of sensing inclination, vibration, and shock experiences by the vehicle's components as it progresses along the path of proving ground. In this study, the instrumented vehicle was driven over 1.44 kilometers of the British Millbrook accredited proving ground Belgian pave driving range in order to measure the response-time history. Due to the severe suspension input received, the vehicle was driven with a constant speed of $50 \mathrm{~km} / \mathrm{h}$. The Belgian road is commonly used for testing vehicle durability since it has 100 times the severity in comparison with general roads [13]. Several passes of proving ground road surface were collected to ensure a statistically valid and representative sample of data. The component responses towards the loads are simultaneously recorded as a time history on the EDAQ.

2.5. Durability Test Rig. The acquired time history from the proving ground data acquisition is utilized in the system and component level fatigue durability test using spindle coupled full vehicle road simulator. In this study the MTS 329 multiaxial spindle coupled road simulator shown in Figure 5 is used for the laboratory testing.

This system allows the excitation of each of the six degree of freedom which is translation in $x, y, z$ and rotation around these axes with the simulation range of up to $50 \mathrm{~Hz}$. Remote Parameter Control RPC iterative deconvolution technique is used in order to accurately replicate the load time history obtained from the proving ground. The replicated knuckle vertical direction load-time history for a segment of $1.44 \mathrm{~km}$ Belgian Pave is shown in Figure 6.

2.6. Fatigue Life Estimation. Service load is one of important factors to be considered in fatigue life estimation of automotive components. Components such as the steering 


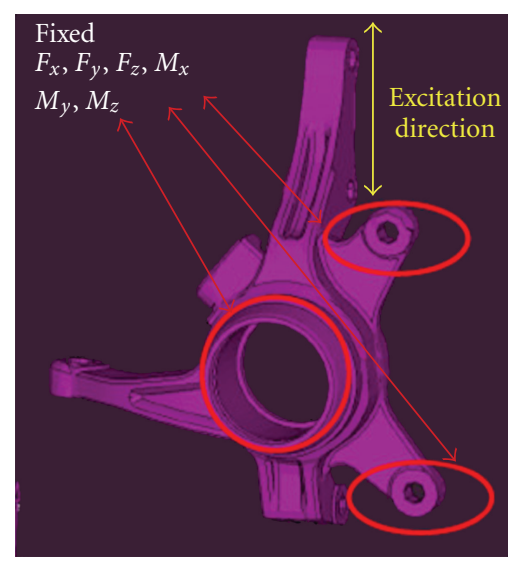

(a)

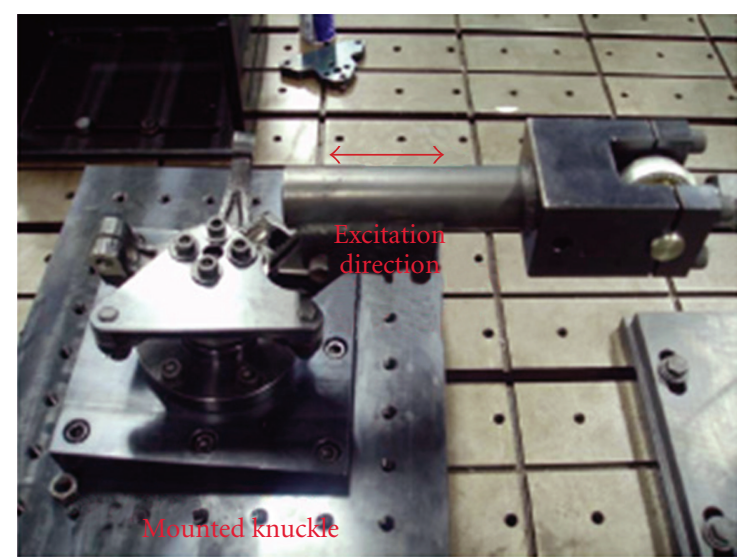

(b)

Figure 4: Cyclic tension test.

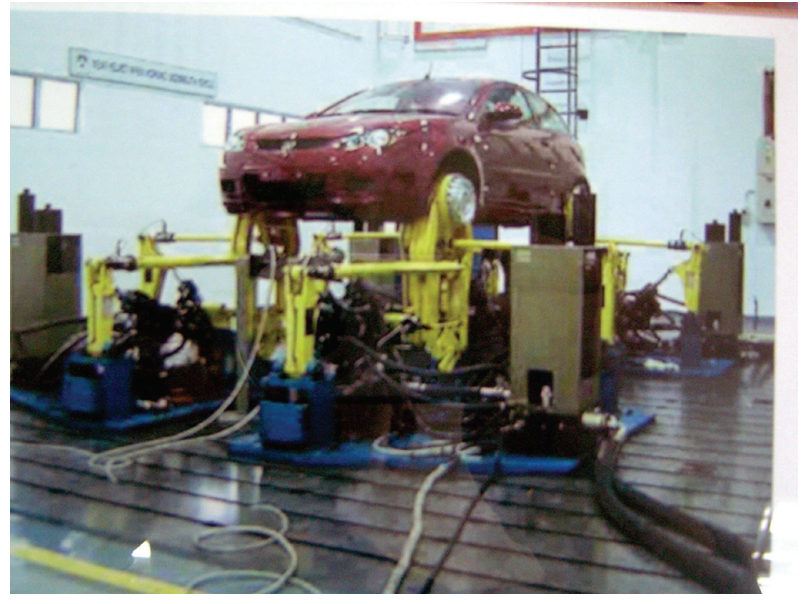

FIGURE 5: MTS 329 multi-axial spindle coupled road simulator.

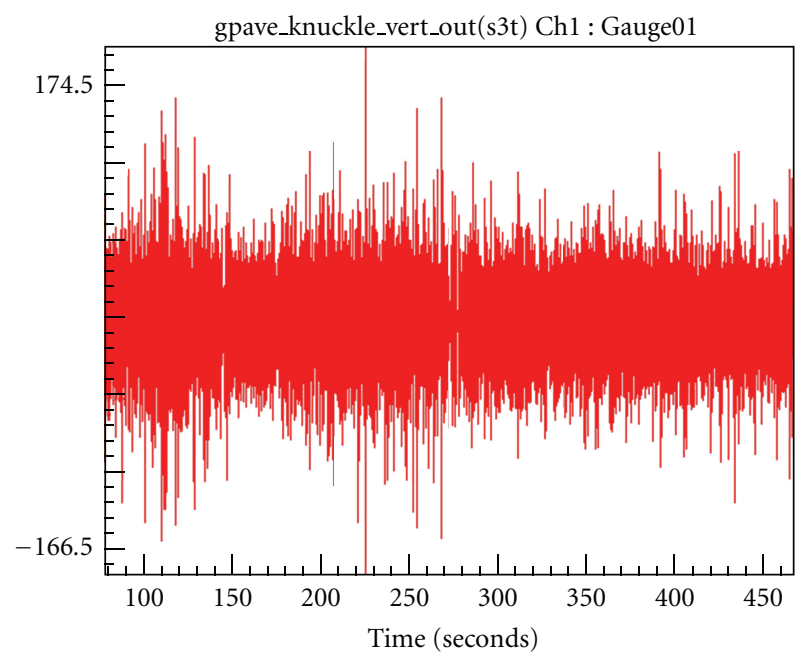

FIGURE 6: Knuckle vertical direction load-time history. knuckle is subjected to stochastic physic failures due to uncertainties in the service loads arising from driving condition and operating environment. In this study, fatigue analysis software the nCode Glyphworks is applied to predict the fatigue life of the components by combining the information from loads obtained from the road simulator and material properties of the component by fatigue damage accumulation theory. In terms of loads obtained from the road simulator, response of components towards load patterns is expressed as a stress time history. In case where the response time history is made up of constant amplitude stress cycles then the cycle-to-failure can be determined using typical SN diagram. However, this condition does not apply in the case of steering knuckle where the load-time histories obtained from the road simulator are generally in the form of variable amplitude stress signals. This condition requires an empirical approach to be applied in order to evaluate the damage caused by the stress signals. Fatigue life estimates of the steering knuckle were determined by stresslife (SN) method employing Palmgren-Miner rule along with rainflow cycle counting procedure. This approach estimates number of amplitudes of blocks can be applied before failure occurs.

Segmentation of the load-time data was done by implementing a rainflow cycle extraction algorithm in order to segment the load-time histories into maximum and minimum amplitude as well as the number of occurrences for certain amplitude ranges. Figure 7 shows the load-time data segmentation in the form of rainflow cycle matrix for the steering knuckle vertical load direction. Fatigue life of the component was then estimated by combining information from rainflow cycle extraction of the service loads and the fatigue life curve of the component material. In this analysis, the Gerber's mean stress correction was applied in dealing with residual stress that would affect the rate of fatigue damage. In terms of local stress approach, Gerber's mean stress correction tends to provide more accurately predicted fatigue lives as compared with experimental lives [5]. 


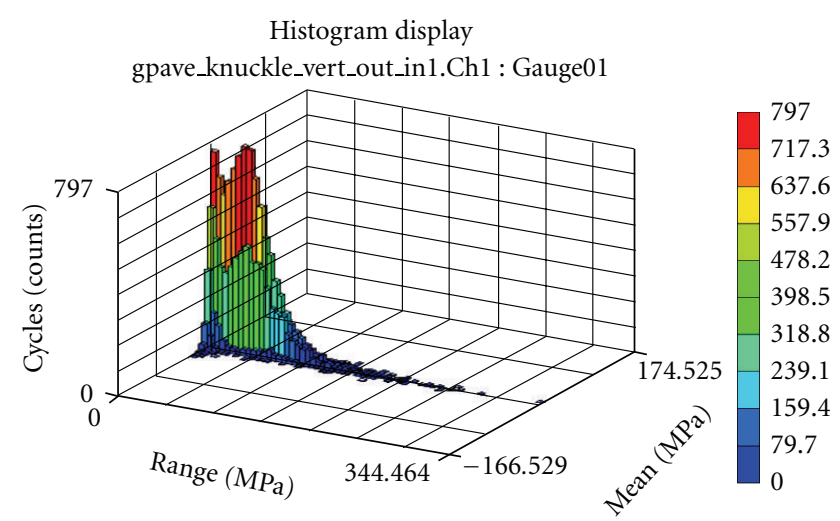

FIGURE 7: Rainflow cycle matrix for the steering knuckle vertical load direction.

TABle 3: Results of cyclic tension test.

\begin{tabular}{lccc}
\hline $\begin{array}{l}\text { Sample } \\
\text { no. }\end{array}$ & $\begin{array}{c}\text { Load amplitude } \\
(N)\end{array}$ & $\begin{array}{c}\text { Stress amplitude } \\
(\mathrm{MPa})\end{array}$ & $\begin{array}{c}\text { Crack initiation } \\
\text { cycle }\end{array}$ \\
\hline 1 & 7259 & 398 & 350000 \\
2 & 7259 & 398 & 400000 \\
3 & 7259 & 398 & 430000 \\
4 & 7259 & 398 & 930000 \\
5 & 7971 & 427 & 221447 \\
6 & 7971 & 427 & 277196 \\
7 & 7971 & 427 & 464274 \\
8 & 8829 & 458 & 113500 \\
9 & 8829 & 458 & 173554 \\
10 & 8829 & 458 & 230000 \\
\hline
\end{tabular}

\section{Results and Discussion}

3.1. Probabilistic SN Curve. A sample of ten units of steering knuckles was subjected to vertical load cyclic tension test and the result is shown in Table 3. Distribution of fatigue life (crack initiation cycles) was identified using three criteria which is the average goodness-of-fit, plot normalization, and log likelihood function with respective decision weights of $50 \%, 20 \%$, and $30 \%$. It is found that two-parameter Weibull distribution function provides the best fit to crack initiation cycle at each stress levels.

The probability distribution function (PDF) of twoparameter Weibull distribution is represented by (1) where $\alpha$ and $\beta$ is scale and shape parameters, respectively.

$$
f(x)=\frac{\beta}{x}\left(\frac{x}{\alpha}\right)^{\beta} e^{-(x / \alpha)^{\beta}} .
$$

The result of cyclic tension test was divided in terms of number of crack initiation cycles corresponding to each stress level. The scale and shape parameter of Weibull distribution for each stress level is then computed using Bernard's median rank and regression analysis. The result is shown in Table 4.

The probability of failure and the probability of survival for two-parameter Weibull distribution are given by (2)
TABLE 4: Weibull distribution parameters.

\begin{tabular}{lccc}
\hline $\begin{array}{l}\text { Stress amplitude } \\
(\mathrm{MPa})\end{array}$ & $\begin{array}{c}\text { Crack initiation } \\
\text { cycles }\end{array}$ & $\begin{array}{c}\text { Scale } \\
\text { parameter, } \alpha\end{array}$ & $\begin{array}{c}\text { Shape } \\
\text { parameter, } \beta\end{array}$ \\
\hline \multirow{4}{*}{398} & 350000 & & \\
& 400000 & 579600 & 2.73 \\
& 430000 & & \\
& 930000 & & \\
\hline \multirow{4}{*}{427} & 221447 & & \\
& 277196 & 362820 & \\
\hline & 464274 & & \\
458 & 113500 & & \\
& 173554 & 195930 & \\
& 230000 & & \\
\hline
\end{tabular}

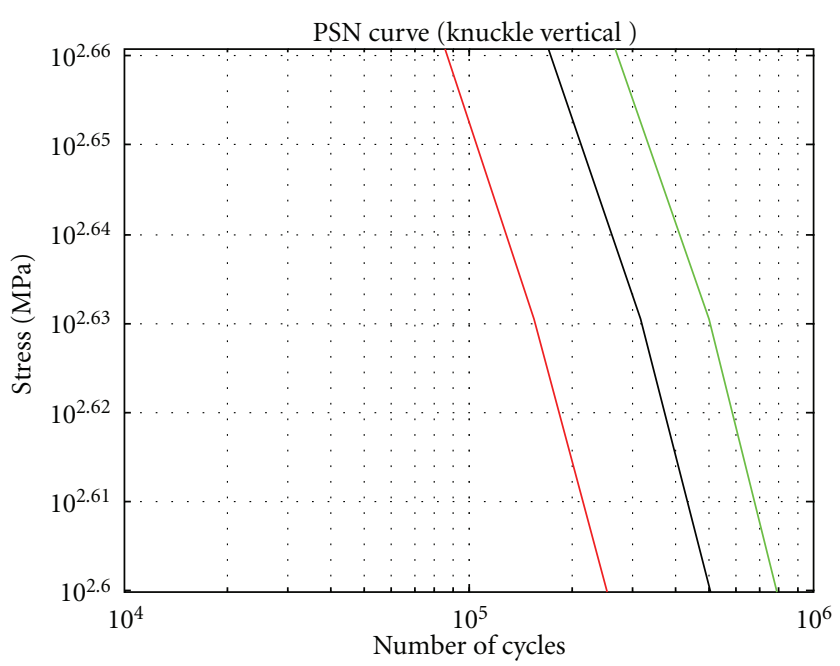

$-90 \%$ survival
$-50 \%$ survival
$-10 \%$ survival

FIGURE 8: Probabilistic stress-life curve (PSN).

and (3), respectively. In this study, as shown in Figure 8, probabilistic stress-life (PSN) plots were drawn for the values of $\mathrm{P}_{10}, \mathrm{P}_{50}$, and $\mathrm{P}_{90}$ ( or $\mathrm{R}_{90}, \mathrm{R}_{50}$ and $\mathrm{R}_{10}$ ). The median life value ( $50 \%$ life) is given by the PSN plot of $\mathrm{P}_{50}\left(\right.$ or $\left.\mathrm{R}_{50}\right)$.

$$
\begin{gathered}
F_{f(x)}=1-e^{-(x / \alpha)^{\beta}}, \\
F_{f(s)}=1-F_{f(x)} .
\end{gathered}
$$

3.2. Fatigue Life Reliability. The mean value of material property of the steering knuckle (represented by PSN plot of $50 \%$ survival) has been obtained by a set of cyclic tension test. As a result, the experimental data have the standard deviation and it is difficult to ensure that the actual material used in the fabrication of the knuckle is closely matched to the known mean value. In this case, it is necessary to evaluate the degree of reliability of the estimated fatigue life of the component.

Variation in the fatigue life curve which characterized the uncertainties appearing in mechanical properties is known 


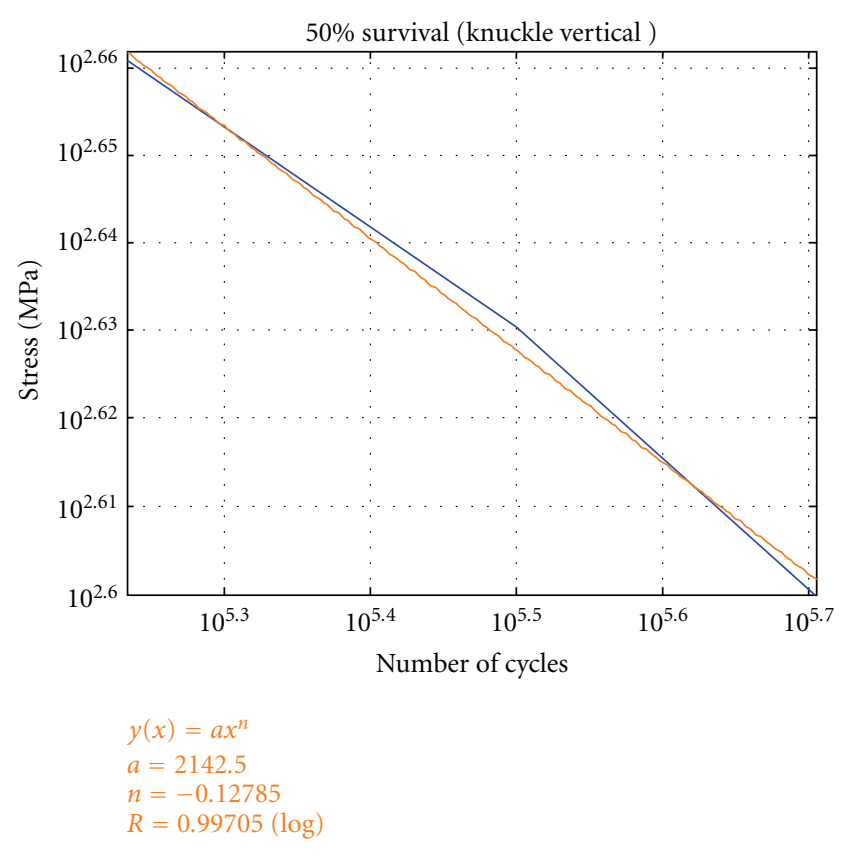

FIgURE 9: Mean life probabilistic SN curve.

to influence the fatigue performance [14]. The distribution properties of the fatigue life curve can be taken from the expert judgements reported in various literatures [15]. The most well-known and classical distribution function is the normal distribution function which is characterized by the mean value and the standard deviation. The coefficient of variation which is a normalized measure of dispersion of a probability distribution is known often from experience and depends on the uniformity of the quality of the component [16].

The fatigue life reliability was evaluated by developing a Pearson statistical model of selected random variables. The Pearson system which is a parametric family of distributions can be used to model a broad scale of distributions with excellent accuracy [17]. Four statistical moments which is the mean, standard deviation, skewness, and kurtosis were selected as the first to fourth statistical moments of the Pearson system. Three levels and weight, with respect to each variable, were used in the fatigue life prediction. In the case of stress-life method, the primary factor which influences the fatigue life is the $\mathrm{SN}$ curve. In this case, elastic modulus and density does not seriously affect the fatigue life as compared to the SN curve [14]. In the developed Pearson model, three levels and weight with respect to each variable were used to predict the fatigue life. The selected variables are the slope, $n$ and the stress range intercept, $a$ of the mean life probabilistic SN curve as shown in Figure 9.

In the case of spheroidal graphite cast iron, the variation in material property is typically assumed normally distributed for it is a reasonable model for many natural processes or physical properties [10]. Consequently, the two selected variables are assumed to be the normal distribution
TABLE 5: Moments of random variables.

\begin{tabular}{lcc}
\hline & Stress range intercept SRI & Slope $b_{1}$ \\
\hline Mean $(\mu)$ & 2142.5 & 0.12785 \\
Standard deviation $(\sigma)$ & 21.425 & 0.0012785 \\
Skewness $\left(\sqrt{\beta_{1}}\right)$ & 0 & 0 \\
Kurtosis $\left(\beta_{2}\right)$ & 3 & 3 \\
\hline
\end{tabular}

TABLE 6: Level and weight of random variables.

\begin{tabular}{lcc}
\hline Variable & Level $_{1-3}$ & Weight $_{1-3}$ \\
\hline \multirow{3}{*}{ SRI $_{1}$} & 2105.39 & 0.1667 \\
& 2142.50 & 0.6667 \\
& 2179.61 & 0.1667 \\
\hline \multirow{3}{*}{$b_{1}$} & 0.1256 & 0.1667 \\
& 0.1279 & 0.6667 \\
& 0.1301 & 0.1667 \\
\hline
\end{tabular}

with a coefficient of variation of 0.01 . The moments of the two variables are shown in Table 5 .

The levels $\left(l_{1-3}\right)$ and weights $\left(w_{1-3}\right)$ of each variable can be calculated based on the defined moments using (4). The calculated levels and weights of the random variables are shown in Table 6.

$$
\begin{aligned}
&\left\{l_{1}, l_{2}, l_{3}\right\}^{T}= {\left[\begin{array}{c}
\mu+\frac{\sqrt{\beta_{1}} \sigma}{2}-\frac{\sigma}{2} \sqrt{4 \beta_{2}-3 \beta_{1}} \\
\mu \\
\mu+\frac{\sqrt{\beta_{1}} \sigma}{2}+\frac{\sigma}{2} \sqrt{4 \beta_{2}-3 \beta_{1}}
\end{array}\right], } \\
&\left\{w_{1}, w_{2}, w_{3}\right\}^{T}=\left[\begin{array}{c}
\frac{\left(4 \beta_{2}-3 \beta_{1}\right)+\sqrt{\beta_{1}} \sqrt{4 \beta_{2}-3 \beta_{1}}}{2\left(4 \beta_{2}-3 \beta_{1}\right)\left(\beta_{2}-\beta_{1}\right)} \\
\frac{\beta_{2}-\beta_{1}-1}{\beta_{2}-\beta_{1}} \\
\frac{\left(4 \beta_{2}-3 \beta_{1}\right)-\sqrt{\beta_{1}} \sqrt{4 \beta_{2}-3 \beta_{1}}}{2\left(4 \beta_{2}-3 \beta_{1}\right)\left(\beta_{2}-\beta_{1}\right)}
\end{array}\right] .
\end{aligned}
$$

Since two variables were selected $\left(b_{1}\right.$ and $\left.\mathrm{SRI}_{1}\right)$, a total of nine fatigue lives and their weight can be calculated as shown in Table 7. Each fatigue life of the steering knuckle was calculated by the linear damage rule stress-life method using the SN curve SRI $I_{1}$ and $b_{1}$ of Table 6 and cycle of the loads obtained from the road simulator. The fatigue life weights are calculated by multiplying each weight with respect to $\mathrm{SRI}_{1}$ and $b_{1}$. 
TABLe 7: Fatigue life results and weights.

\begin{tabular}{lccc}
\hline $\mathrm{SRI}_{1}$ & $b_{1}$ & Fatigue life (cycles) & Weight \\
\hline 2105.39 & 0.1256 & 11740 & 0.02778 \\
2105.39 & 0.1279 & 9753 & 0.11111 \\
2105.39 & 0.1301 & 8308 & 0.02778 \\
2142.50 & 0.1256 & 13000 & 0.11111 \\
2142.50 & 0.1279 & 10750 & 0.44444 \\
2142.50 & 0.1301 & 9229 & 0.11111 \\
2179.61 & 0.1256 & 14300 & 0.02778 \\
2179.61 & 0.1279 & 11950 & 0.11111 \\
2179.61 & 0.1301 & 9995 & 0.02778 \\
\hline
\end{tabular}

TABLE 8: Moments of the fatigue life data.

\begin{tabular}{lc}
\hline Mean $\left(\mu_{g}\right)$ & 10890.86 \\
Standard deviation $\left(\sigma_{g}\right)$ & 1276.30 \\
Skewness $\left(\sqrt{\beta_{1 g}}\right)$ & 0.54 \\
Kurtosis $\left(\beta_{2 g}\right)$ & 3.16 \\
\hline
\end{tabular}

The first to fourth statistical moments of the Pearson system were calculated using (5).

$$
\left\{\mu_{g}, \sigma_{g}, \sqrt{\beta_{1}}, \beta_{2 g}\right\}^{T}=\left[\begin{array}{c}
\sum_{i=1}^{m} q_{i} \cdot g\left(L_{i}\right) \\
\left\{\sum_{i=1}^{m} q_{i}\left(g\left(L_{i}\right)-\mu_{g}\right)^{2}\right\}^{1 / 2} \\
\frac{\left\{\sum_{i=1}^{m} q_{i}\left(g\left(L_{i}\right)-\mu_{g}\right)^{3}\right\}}{\sigma_{g}^{3}} \\
\frac{\left\{\sum_{i=1}^{m} q_{i}\left(g\left(L_{i}\right)-\mu_{g}\right)^{4}\right\}}{\sigma_{g}^{4}}
\end{array}\right] .
$$

Table 8 shows the first through fourth moments of the probability density function calculated using nine fatigue life estimates of the steering knuckle.

Equation (6) represents the Pearson's criterion for fixing the distribution family based on the selected statistical moments.

$$
K=\frac{\beta_{1}\left(\beta_{2}+3\right)^{2}}{4\left(4 \beta_{2}-3 \beta_{1}\right)\left(2 \beta_{2}-3 \beta_{1}-6\right)} .
$$

The type of the Pearson system and probability density function differs depending on the value of $K$ as shown in Table 9.

Based on the moments calculated in Table 8 , it is found that the value of $K=-0.3594$ which represents Type I of the Pearson system. The probability density function of the Beta distribution was calculated using MATLAB statistical toolbox and the probability density function of the steering knuckle fatigue life is shown in Figure 10.

Fatigue life range calculated from the Beta distribution is distributed from 6000 to 16000 cycles. The fatigue life reliability of the steering knuckle is shown in Table 10. The

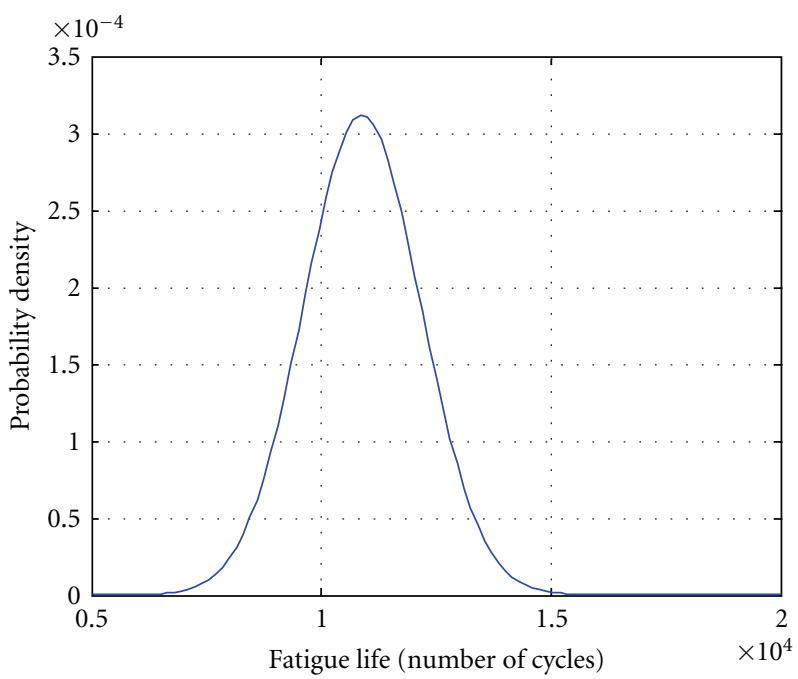

FIGURE 10: Probability density function of the steering knuckle.

fatigue life of the steering knuckle is found to have the lowest reliability between 14000 and 16000 cycles. The highest fatigue life reliability is recorded for 10000-12000 cycles.

\section{Conclusions}

In this study, the fatigue life of the steering knuckle is predicted for a passenger car and the predicted fatigue life reliability is evaluated by considering the variations in material properties. Based on the analyses presented, the following conclusions can be made.

(1) In terms of multiaxial loads experience by the steering knuckle, loads in the vertical direction provide greatest damage and the shortest fatigue life.

(2) The slope and intercept of the SN curve, which mostly affects the fatigue life results, are selected as random variables in the Pearson fatigue life reliability evaluation. It is found that the fatigue life of the steering knuckle to have the lowest reliability between 14000 and 16000 cycles. The highest reliability is recorded for cycles between 10000 and 12000 cycles which include the 10891 cycles calculated by the mean value of material property.

(3) The use of a statistical method to evaluate the expected life has the advantage that replacement time and failure probability of the parts can be predicted in advance. For example, assuming that a steering knuckle life has 16000 cycles which is the cycle range of lowest reliability, the vehicle will be safe to travel $23040 \mathrm{~km}$ at a speed of $50 \mathrm{~km} /$ hour. Since the Belgian road has 100 times the severity of the general road, the life of the steering knuckle is relatively long, compared with the life cycle of the general vehicle. 
TABle 9: Type of Pearson system and probability function.

\begin{tabular}{|c|c|c|c|c|c|c|}
\hline Type I & Type II & Type III & Type IV & Type V & Type VI & Type VII \\
\hline$K<1$ & $K=0, \beta_{1}=0, \beta_{2}<3$ & $\begin{array}{c}K=\infty \\
2 \beta_{2}=3 \beta_{1}-6=0\end{array}$ & $0<K<1$ & $K=1$ & $K>1$ & $K=0, \beta_{1}=0, \beta_{2}>3$ \\
\hline $\begin{array}{l}\text { Normal/Beta } \\
\text { distribution }\end{array}$ & Special case of Type I & $\begin{array}{c}\text { Chi-square/Gamma } \\
\text { distribution }\end{array}$ & $\begin{array}{c}\text { Cauchy } \\
\text { distribution }\end{array}$ & $\begin{array}{l}\text { Inverse-gamma } \\
\text { distribution }\end{array}$ & $\begin{array}{c}\text { Beta-prime/F } \\
\text { distribution }\end{array}$ & Student's $t$ distribution \\
\hline
\end{tabular}

TABLE 10: Fatigue life reliability of steering knuckle.

\begin{tabular}{lccccc}
\hline Cycles & $6000-8000$ & $8000-10000$ & $10000-12000$ & $12000-14000$ & $14000-16000$ \\
\hline Reliability & 0.0117 & 0.2310 & 0.5651 & 0.1848 & 0.0074 \\
\hline
\end{tabular}

The method described in this study can be effectively applied in the determination of probability of failure of massproduced parts where lack of uniformity in quality of the material procured is the main challenge. In this study, the use of a statistical method to evaluate the expected life of an automotive component has the advantage in estimating the replacement time and failure probability of the component.

\section{Acknowledgments}

The presented methodologies are parts of research project "Reliability Prediction in Automotive Component Design" which is supported by the Research and Vehicle Engineering Division, Perusahaan Otomobil Nasional Sdn Bhd (PROTON). This project is partly funded by the Malaysian Ministry of Science, Technology and Innovation (MOSTI) escience research grant 01-01-02-SF03066.

\section{References}

[1] G. K. Triantafyllidis, A. Antonopoulos, A. Spiliotis, S. Fedonos, and D. Repanis, "Fracture characteristics of fatigue failure of a vehicle's ductile iron steering knuckle," Journal of Failure Analysis and Prevention, vol. 9, no. 4, pp. 323-328, 2009.

[2] R. L. Jhala, K. D. Kothari, and S. S. Khandare, "Component fatigue behaviors and life predictions of a steering knuckle using finite element analysis," in Proceedings of the International MultiConference of Engineers and Computer Scientists, Hong Kong, March 2009.

[3] J. Devlukia, H. Bargmann, and I. Rüstenberg, "Fatigue assessment of an automotive suspension component using deterministic and probabilistic approaches," European Structural Integrity Society, vol. 22, pp. 1-16, 1997.

[4] N. W. M. Bishop and F. Sherratt, Finite Element Based Fatigue Calculations, NAFEMS Ltd., October 2000.

[5] M. Zoroufi and A. Fatemi, "Experimental durability assessment and life prediction of vehicle suspension components: a case study of steering knuckles," Proceedings of the Institution of Mechanical Engineers Part D, vol. 220, no. 11, pp. 15651579, 2006.

[6] R. I. Stephens, A. Fatemi, R. R. Stephens, and H. O. Fuchs, Metal Fatigue in Engineering, Wiley Interscience, New York, NY, USA, 2nd edition, 2001.

[7] A guide for fatigue testing and statistical analysis of fatigue data, American Society for Testing and Materials, Philadelphia, Pa, USA, 1963, ASTM STP No. 91-A.
[8] J. D. Booker, M. Raines, and K. G. Swift, Designing Capable and Reliable Products, Butterworth-Heinemann, Oxford, UK, 2001.

[9] P. W. Hovey, A. P. Berens, and D. A. Skinn, "Risk analysis for aging aircraft," in Flight Dynamic Directorate, vol. 1, Wright Laboratory, Dayton, Ohio, USA, October 1991.

[10] R. E. Melchers, Structural Reliability Analysis and Prediction, John Wiley \& Sons, Chichester, UK, 2nd edition, 1999.

[11] J. Schijve, "Statistical distribution functions and fatigue of structures," International Journal of Fatigue, vol. 27, no. 9, pp. 1031-1039, 2005.

[12] J. D. Kim and J. K. Ji, "Effect of super-rapid induction quenching on fatigue fracture behavior of spherical graphite cast iron FCD500," Journal of Materials Processing Technology, vol. 176, no. 1-3, pp. 19-23, 2006.

[13] K. J. Jun, T. W. Park, S. H. Lee, S. P. Jung, and J. W. Yoon, "Prediction of fatigue life and estimation of its reliability on the parts of an air suspension system," International Journal of Automotive Technology, vol. 9, no. 6, pp. 741-747, 2008.

[14] J. A. Bannantine, J. J. Comer, and J. L. Handrock, Fundamentals of Metal Fatigue Analysis, Prentice Hall, Upper Saddle River, NJ, USA, 1989.

[15] B. Sudret, Z. Guede, P. Hornet, J. Stephan, and M. Lemaire, "Probabilistic assessment of fatigue life including statistical uncertainties in the SN curve," in Proceedings of the 17th International Conference on Structural Mechanics in Reactor Technology, Prague, Czech Republic, August 2003.

[16] G. Genet, A Statistical Approach to Multi-Input Equivalent Fatigue Loads for the Durability of Automotive Structures, Chalmers University of Technology and Goteborg University, Goteborg, Sweden, 2006.

[17] G. J. Hahn and S. S. Shapiro, Statistical Models in Engineering, John Wiley \& Sons, New York, NY, USA, 1967. 

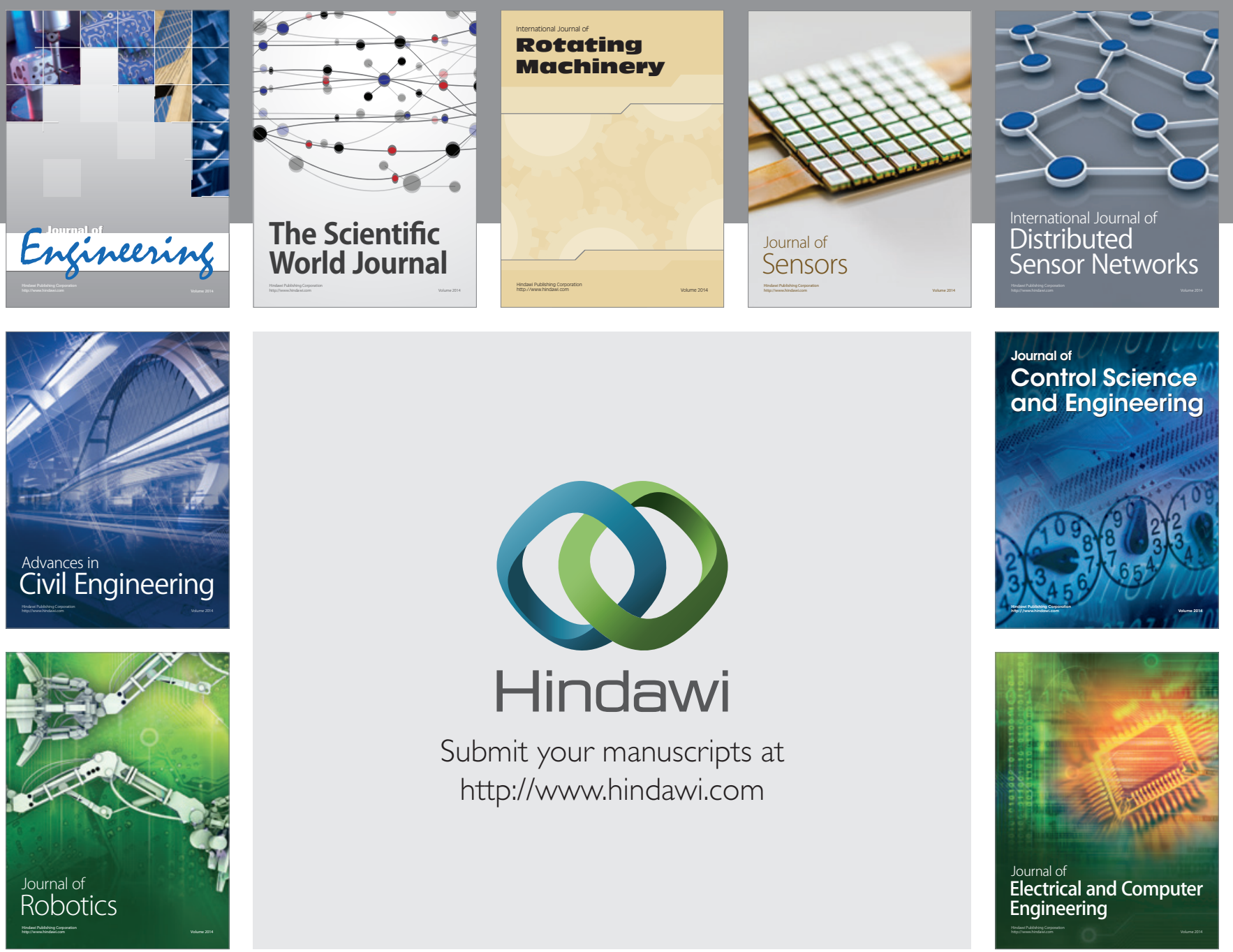

Submit your manuscripts at

http://www.hindawi.com
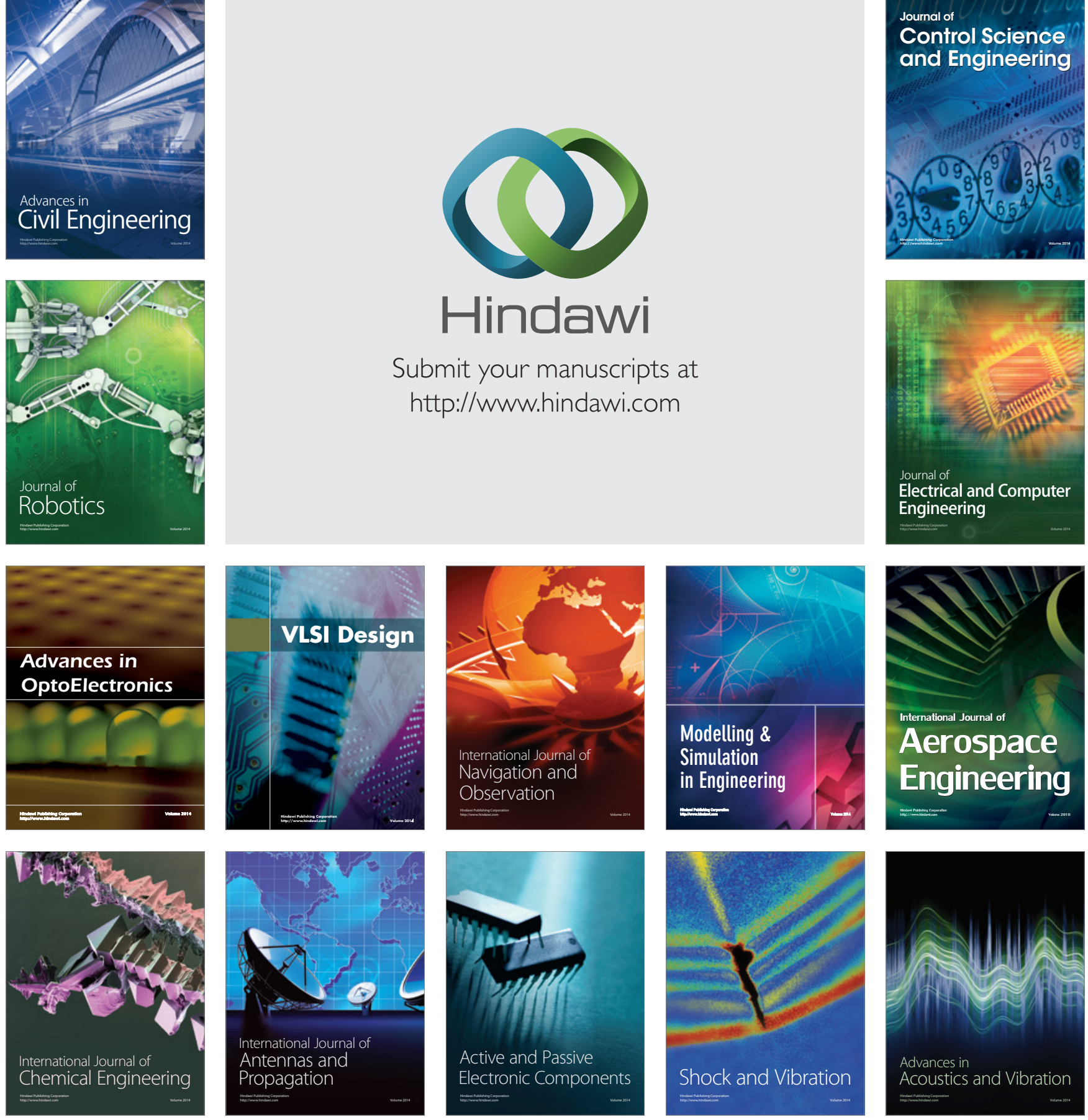